\title{
ON THE NORMALIZED NUMERICAL RANGE
}

\author{
ILYA M. SPITKOVSKY AND ANDREI-FloriAn STOICA
}

Abstract. The normalized numerical range of an operator $A$ is defined as the set $F_{N}(A)$ of all the values $\langle A x, x\rangle /\|A x\|$ attained by unit vectors $x \notin \operatorname{ker} A$. We prove that $F_{N}(A)$ is simply connected, establish conditions for it to be star-shaped with the center at zero, to be open, closed, and to have empty interior. For some classes of operators (weighted shifts, isometries, essentially Hermitian) the complete description of $F_{N}(A)$ is obtained.

Mathematics subject classification (2010): 15A60, 47A12, 47B15.

Keywords and phrases: Numerical range, normalized numerical range, partial isometry, essentially Hermitian operator, weighted shift.

\section{REFERENCES}

[1] W. AuZInger, Sectorial operators and normalized numerical range, Appl. Numer. Math. 45 (4): 367-388, 2003.

[2] D. Corey, C. Johnson, R. Kirk, B. Lins, And I. M. Spitkovsky, The product field of values, Linear Algebra Appl. 438: 2155-2173, 2013.

[3] Ju. L. DAleckiI And M. G. Krein, Stability of solutions of differential equations in Banach space, American Mathematical Society, Providence, R. I., 1974.

[4] D. S. DJORDJEvić, Characterizations of normal, hyponormal and EP operators, J. Math. Anal. Appl. 329 (2): 1181-1190, 2007.

[5] E. DuRSZT, On the numerical range of normal operators, Acta Sci. Math. (Szeged), 25: 262-265, 1964.

[6] L. Z. GEVORGYAN, On the convergence rate of iterations and the normalized numerical range of an operator, Math. Sci. Res. J. 8 (1): 16-26, 2004.

[7] L. Z. Gevorgyan, On some properties of the normalized numerical range, Izv. Nats. Akad. Nauk Armenii Mat. 41 (1): 41-48, 2006.

[8] L. Z. Gevorgyan, An example of the normalized numerical range, Armenian J. Math. 1 (1): 50-33, 2009.

[9] L. Z. Gevorgyan, Normalized numerical ranges of some operators, Operators and Matrices 3 (1): 145-153, 2009.

[10] L. Z. Gevorgyan, Normalized numerical ranges of some complex $2 \times 2$ matrices, Izv. Nats. Akad. Nauk Armenii Mat. 46 (5): 41-52, 2011.

[11] K. E. Gustafs On And D. K. M. RaO, Numerical Range. The Field of Values of Linear Operators and Matrices, Springer, New York, 1997.

[12] P. Halmos, A Hilbert Space Problem Book, Van Nostrand, Princeton, N. J., 1967.

[13] R. A. Horn And C. R. Johnson, Topics in matrix analysis, Cambridge University Press, Cambridge, 1994. Corrected reprint of the 1991 original.

[14] L. V. Kantorovich, Functional analysis and applied mathematics, Uspehi Matem. Nauk (N. S.), 3 (6 (28)): 89-185, 1948.

[15] L. V. KAntorovich, Functional analysis and applied mathematics, NBS Rep. 1509. U. S. Department of Commerce, National Bureau of Standards, Los Angeles, Calif., 1952., translated by C. D. Benster.

[16] W. C. RIDGE, Numerical range of a weighted shift with periodic weights, Proc. Amer. Math. Soc. 55: 107-110, 1976.

[17] Q. F. Stout, The numerical range of a weighted shift, Proc. Amer. Math. Soc. 88: 495-502, 1983. 
[18] B. SZ.-NAGy, C. Foias, H. Bercovici, AND L. KérChy, Harmonic analysis of operators on Hilbert space, Universitext, Springer, New York, second edition, 2010.

[19] K.-Z. WAng And P. Y. WU, Numerical ranges of weighted shifts, J. Math. Anal. Appl. 381 (2): 897-909, 2011. 